\title{
Root endophytic fungal communities associated with pitch pine, switchgrass and rosette grass in the pine barrens ecosystem
}

Jing LUO ${ }^{a}$, Emily WALSH ${ }^{a}$, Stephen MILLER ${ }^{a}$, David BLYSTONE ${ }^{a}$, John DIGHTON ${ }^{b}$, Ning ZHANG ${ }^{a, c, *}$

${ }^{a}$ Department of Plant Biology and Pathology, 201 Foran Hall, 59 Dudley Road, Rutgers University, New Brunswick, New Jersey 08901, USA

${ }^{b}$ Rutgers Pinelands Field Station, DEENR, SEBS and Biology, Camden

PO Box 206, 501 Four Mile Road, New Lisbon, New Jersey 08064, USA

${ }^{c}$ Department of Biochemistry and Microbiology, 76 Lipman Drive, Rutgers University,

New Brunswick, New Jersey 08901, USA

"Corresponding author.

Tel: +1 848-932-6348

Fax: +1 732-932-3844

Email address: zhang@ aesop.rutgers.edu

(C) 2017. This manuscript version is made available under the Elsevier user license http://www.elsevier.com/open-access/userlicense/1.0/ 


\begin{abstract}
Almost all plants in nature harbor fungi in their roots but the knowledge on distribution and the underlying principles of assemblage is still poorly developed for the root-associated fungi. In this study we analyzed the root endophytic fungal communities associated with switchgrass, rosette grass, and pitch pine in the acidic, oligotrophic pine barrens ecosystem. A total of 434 fungal isolates were obtained from 600 root segments of 60 plant samples. DNA barcoding and morphological analyses identified 92 fungal species, which belong to 39 genera in 6 classes. Compared to other ecosystems, the pine barrens has a higher proportion of Leotiomycetes. The fungal community associated with pitch pine was significantly different from those associated with the grasses, while less difference was found between those associated with the two grasses. Our results suggest that edaphic factors and host specificity play a role in shaping root endophytic fungal community. This study also corroborates our previous finding that plant roots in the pine barrens are a rich reservoir of novel fungi.
\end{abstract}

Keywords:

Endophytes

Fungal ecology

Host specificity

Pine barrens

Root-associated fungi

Switchgrass 


\section{Introduction}

Fungal endophytes refer to fungi that colonize living plant tissue without causing any immediate, overt negative effects to the hosts (Hirsch and Braun 1992). Root fungal endophytes reside within plant roots for all or part of their life cycle (Sieber 2002). The concept of root endophytes used in this paper is in the broad sense that includes all symbiotic fungi from surface sterilized roots of apparently healthy plants. In practice, certain mycorrhizal and pathogenic species may also be isolated.

Fungal root endophytes are ubiquitous and have been reported from a wide host range including ferns, lycophytes, conifers and angiosperms (Jumpponen and Trappe 1998; Rodriguez et al. 2009; Zubek et al. 2010). Some root endophytes were reported to play a role in deterring pathogens, decreasing herbivory, and enhancing host plant's tolerance to biotic and abiotic stresses. However, the functions of most root endophytes remain elusive due to the inconsistent results or simply the lack of study (Mandyam and Jumpponen 2005; Rodriguez et al. 2009).

Fungal root endophytes are taxonomically diverse. Various Ascomycota, Basidiomycota and Mucoromycotina fungi have been isolated from plant roots, among which Ascomycota fungi are usually predominant. For example, $96 \%$ fungal root endophytes isolated from three boreal tree species belonged to Ascomycota (Kernaghan and Patriquin 2011). High proportion of species belonging to Ascomycota was also reported from Arabidopsis thaliana (89\%) (Keim et al. 2014), Microthlaspi perfoliatum (100\%) (Keim et al. 2014), Holcus lanatus (97\%) (Sánchez Márquez et al. 2010), Dactylis glomerata (98\%) (Sánchez Márquez et al. 2007), Oryzae granulate (98\%) (Yuan et al. 2010), and Pseudotsuga menziesii and Pinus ponderosa (52\%) (Hoff et al. 2004). Within Ascomycota, Sordariomycetes and Dothideomycetes were reported as the predominant classes in most studies (Keim et al. 2014; Khidir et al. 2010; Sánchez Márquez et al. 2007, 2010; Yuan et al. 2010). However, recent studies using a culture-independent metabarcoding method revealed that Basidiomycota fungi and other unculturable or slow growing fungi account for a large proportion of the root fungal community (Mundra et al. 2015).

Many fungal pathogens and endophytes of leaves or stems are host-specific (Butin 1986; Fisher et al. 1995; Newton and Haigh 1998; Wood and Graniti 1976; Zhou and Hyde 2001). Root endophytes, however, were generally believed to be less host-specific and have broad host ranges (Jumpponen and Trappe 1998; Rodriguez et al. 2009). For example, Phialocephala fortinii, a wide spread root endophyte was found to be associated with more than 20 plant species (Jumpponen and Trappe 1998). However, more recent molecular phylogenetic studies indicated that $P$. fortinii is a species complex, within which each cryptic species may be associated with a narrower host range (Grünig et al. 2004, 2008a, 2008 b). Several other recent studies also demonstrated that different host plant species harbor different root endophyte communities (Keim et al. 2014; Kernaghan and Patriquin 2011). However, the data on the root endophyte distribution in various host plants and ecosystems are still very limited, and our knowledge on the underlying principles of root 
endophyte community assemblage is poorly developed (Davison et al. 2015; Tedersoo et al. 2014).

New Jersey Pine Barrens is a 1.4 million acre $\left(57,000 \mathrm{~km}^{2}\right)$ coastal plain located in southern New Jersey in the United States. It has a temperate climate with average monthly temperatures from 0.3 to $24.3^{\circ} \mathrm{C}$ and average annual precipitation of $116.5 \mathrm{~cm}$ (1981-2010, NJ State Climatologist). There are more than 850 plant species inhabiting this ecosystem, where pines and oaks are the dominant trees, and the understory is composed of grasses (Poaceae), sedges (Cyperaceae), blueberries and other heath family members (Ericaceae) (Forman 1998, http://nj.gov/pinelands/reserve/plants/). The soils in the pine barrens are highly acidic ( $\mathrm{pH} 4-5$ ), sandy, dry (low moisture holding capacity) and nutrient poor (low in P, K, N) (Forman 1998; Joffe and Watson 1933; Tedrow 1952; Turner et al. 1985). The New Jersey Pine Barrens represents one of a series of barrens ecosystems in the eastern United States and one of a series of similar ecosystems around the world. Only few studies have assessed the fungal diversity in the pine barrens, and much remains unknown about root endophytes in this ecosystem (Forman 1998; Tuininga and Dighton 2004). Our recent survey indicated that plant roots in this acidic, oligotrophic ecosystem harbor diverse fungal endophytes, many of which are undescribed species (Luo et al. 2014a).

In this study, root endophytic fungi associated with one pine and two grass species that are commonly found in the New Jersey Pine Barrens were examined. The objectives were to (1) identify the endophytic fungi inhabiting the pine and grass roots in the pine barrens, and (2) identify the factors that shape the root endophytic fungal communities in this ecosystem.

\section{Materials and methods}

\subsection{Sample collection}

In June 2014, a total of 60 root samples were collected from three common native plant species, i.e., rosette grass (Dichanthelium acuminatum), switchgrass (Panicum virgatum) and pitch pine (Pinus rigida) from Collier's Mills (N4004', W74 $26^{\prime}$ ', Alt. 42m) and Wharton State Forest (N39 46', W7440', Alt. 40m) in the New Jersey Pine Barrens. There is a distance of $64 \mathrm{~km}$ between the two sampling locations. They are both typical sand plains with similar vegetation. Both sites are low density forests composed mostly of pitch pines. The scattered trees or groves are interspersed with openings in which isolated tussocks of rosette grass and switchgrass are prominent. Healthy plants of similar size were chosen and their root samples were collected by digging up the plant root system approximately $50 \mathrm{~cm}$ deep in soil. At each location, 10 apparently healthy root samples including coarse roots, fine roots and root tips were randomly collected for each plant species, at least $5 \mathrm{~m}$ apart to avoid clonal ramets and maximize diversity (Kleczewski et al. 2012). Samples were kept on ice and transported to the laboratory for fungal isolation within $24 \mathrm{~h}$.

\subsection{Fungal isolation}


The collected roots were rinsed in tap water to remove soil particles and cut into 10-20 mm long segments. The segments were surface sterilized with $95 \%$ ethanol for $30 \mathrm{~s}$, followed by $2 \mathrm{~min}$ in $0.6 \%$ sodium hypochlorite and $70 \%$ ethanol for $2 \mathrm{~min}$, then two final rinses in sterile distilled water. Samples from the same host species and same location were pooled and further cut into $3 \mathrm{~mm}$ long small segments. For each of the six pooled samples, 100 surface sterilized $3 \mathrm{~mm}$ long root segments were air dried and placed on $2 \%$ malt extract agar (MEA, BD Difco, Sparks, Maryland) with 0.07\% lactic acid. Lactic acid was used to limit bacterial growth during isolation (Bills and Foster 2004). Plates were incubated at room temperature and observed daily in the first two weeks, then twice a week afterwards for six months. Fungal cultures were isolated and purified by subculturing from emergent hyphal tips. Imprints of root segments were made on MEA plates to confirm the effectiveness of the surface disinfection protocol. No fungal growth was observed from these imprint plates during 4 weeks of incubation. Spore morphology, if present, and colony characteristics were examined and recorded as morphological data for identification. Fungal cultures are preserved at $-80^{\circ} \mathrm{C}$ in glycerol and $4{ }^{\circ} \mathrm{C}$ on agar in the Zhang lab at Rutgers University, USA. Fungal DNA sequences from this study were deposited in GenBank (Table S1).

\subsection{Molecular identification and phylogenetic analysis}

The DNA sequences of the internal transcribed spacer (ITS) of the ribosomal RNA genes were obtained for all the isolated fungal cultures. The PowerSoil DNA Isolation Kit (MoBio, California) was used for DNA isolation, and the primers ITS1 and ITS4 (White et al. 1990) were used for PCR and sequencing. DNA extraction, PCR amplification and sequencing of ITS followed the protocols described in Luo and Zhang (2013). With Usearch 7 (Edgar 2010), the ITS sequences were clustered into operational taxonomic units (OTUs) using 97\% sequence similarity according to O'Brien et al. (2005) and 99\% similarity suggested by Gazis et al. (2011), respectively. The OTUs were then identified based on the search results with Blastn in UNITE (https://unite.ut.ee/), GenBank (http://www.ncbi.nlm.nih.gov/) and AFTOL (http://aftol.org/) databases, as well as the morphological data, which contributed to the identification of the sporulating taxa such as Acidomelania, Barrenia, Curvularia, Fusarium, Magnaporthiopsis, Penicillium, Pseudophialophora, and Umbelopsis. Uncultured environmental samples in the databases were excluded. The close matching sequences were included in our phylogenetic analyses to infer taxonomic assignments (Tables S1, Figs S1-S3). Because the two clustering criteria led to similar conclusions regarding the fungal community structure, only the results from the $97 \%$ similarity clustering were presented in the paper, while the results from the $99 \%$ similarity were provided in the supplementary files (Tables S3-S4, Figs S4-S10). Another reason to prefer the $97 \%$ similarity is that this criterion applied well to the predominant Leotiomycetes and Sordariomycetes species from the pine barrens plant roots (Luo et al. 2014a, 2015b; Walsh et al. 2014, 2015). A species was categorized as undescribed when it was diagnosably distinct from any reference taxon in phylogeny, had 
$<97 \%$ ITS sequence similarity to any known taxon in GenBank, and morphologically, there was no match with available fungal descriptions in the literature.

Phylogenetic analyses that include reference sequences were performed to further confirm the fungal identification. Because fungal ITS sequences are highly variable at higher taxonomic levels (Nilsson et al. 2008), three separate phylogenetic analyses were performed: Sordariomycetes and Leotiomycetes, Dothideomycetes and Eurotiomycetes, and Basidiomycota and Mucoromycotina. All sequences of representative phylotypes were aligned in Clustal X V.1.8 (Thompson et al. 1997) and slightly refined manually in BioEdit 7.0.5 (Hall 1999). MrModeltest (Nylander 2004) was used to specify the best-fit nucleotide substitution model under hierarchical likelihood ratio tests (hLRT) and Akaike information criterion (AIC). The general time reversible with a proportion of invariable sites and gamma distributed rate variation among sites $(\mathrm{GTR}+\mathrm{I}+\mathrm{G})$ was the selected model for the Sordariomycetes and Leotiomycetes, as well as the Dothideomycetes and Eurotiomycetes. The Hasegawa-Kishino-Yano model with a proportion of invariable sites and gamma distributed rate variation among sites $(\mathrm{HKY}+\mathrm{I}+\mathrm{G})$ was used for the third group including Basidiomycota and Mucoromycotina. Maximum likelihood (ML) analyses with the selected models were carried out in PhyML 3.0 (Guindon et al. 2010). Branch support was assessed with 1000 bootstraps replicates.

\subsection{Community analysis}

Fungi isolated from rosette grass (R), switchgrass (S) and pitch pine (P) from Collier's Mills (C) and Wharton State Forest (W) in New Jersey Pine Barrens were abbreviated as $\mathrm{CR}, \mathrm{CS}, \mathrm{CP}, \mathrm{WR}, \mathrm{WS}$ and WP, respectively. Species rarefaction curves, species richness analyses, and diversity indices were calculated using 50 randomizations of sample order in EstimateS 9.1 (Colwell et al. 2012). Chao, Jackknife and Bootstrap values were applied for species richness estimates, and only Chao1 index was provided in Table 1. Fungal diversity was measured using Shannon-Wiener's and Fisher's alpha indices.

The composition of fungal communities was compared among hosts and locations using two similarity indices: Sørenson's (SI) and Jaccard's (JI) indices. Additionally, the relationships among the fungal communities were visualized using nonmetric multidimentional scaling (NMDS) analysis according to Bray Curtis dissimilarities in $\mathrm{R}$ package vegan (Oksanen 2015). The statistical significances of fungal assemblages were evaluated with analysis of similarities (ANOSIM) using distance matrices.

\section{Results}

\subsection{Fungal isolation and identification}

A total of 434 fungal isolates were obtained from 600 root segments of 60 plant samples. Based on ITS sequences and morphology, they were identified to belong to 92 species in 39 genera, 25 families, 18 orders and 6 classes (Fig 1), among which 47 (51\%) species were likely undescribed. The majority $(85.9 \%)$ of these fungal species are in the phylum Ascomycota, including 32 Leotiomycetes species (209 isolates), 25 Sordariomycetes (149 
isolates), 12 Dothideomycetes (28 isolates) and 10 Eurotiomycetes (27 isolates). Only 8 Mucoromycotina (15 isolates) and 5 Basidiomycota species (6 isolates) were uncovered.

There were 96 isolates uncovered from CR, 86 from WR, 76 from WP, 71 from WS, 70 from CP, and 35 from CS (Table 1). The highest fungal species richness was found from CP (33 species), followed by WP (25 species), WR (20 species), CR (19 species), WS (19 species) and CS (13 species). All species rarefaction curves failed to reach asymptote, indicating that more species will likely be found with additional sampling (Fig 2). The species diversity and the estimated richness are listed in Table 1. Based on the calculated Chao1 index, CP had the highest fungal species richness, followed by WS, CR, WP, CS and WR. Additionally, the highest percentage of species captured based on the Chao1 index was found from WR (95.2\%), followed by WP (73.5), CP (61.1\%), CR (54.3\%), WS (51.4\%), and CS (43.3\%), which indicated that more than 50\% species were successfully obtained from most sampling locations except CS. The Shannon's diversity index ranged from 2.01 to 3.11, while Fisher's alpha index was from 7.1 to 24.38 (Table 1).

Distribution of fungal classes found among hosts and locations in the New Jersey Pine Barrens was illustrated in Fig 3. Sordariomycetes and Leotiomycetes were the most frequently isolated fungi in CR, WR, WS and WP, Sordariomycetes and Dothideomycetes were predominant in CS, while Leotiomycetes and others were predominant in CP. At the species level, the most frequently isolated species were listed in Table 1.

Pseudophialophora eragrostis was shared by CR and WR; Acephala sp4 was shared by CR, $\mathrm{CR}$ and WS, and Mollisia sp. was shared by CS and WS. Among the 92 identified fungal species, 24 occurred in two or more communities. There were 19 fungal species exclusive to $\mathrm{CP}, 15$ to WP, 12 to WR, 9 to $\mathrm{CR}, 9$ to $\mathrm{WS}$, and 5 to $\mathrm{CS}$.

\subsection{Difference among hosts and locations}

The pairwise similarity of six samples ranged from 0.438 to 0.044 for the Sørenson's index, and 0.28 to 0.023 for the Jaccard's index (Table 2). The highest similarity was found between CS and CR $(\mathrm{SI}=0.438, \mathrm{JI}=0.28)$, followed by WS and WR $(\mathrm{SI}=0.41, \mathrm{JI}=0.258)$, $\mathrm{CP}$ and $\mathrm{WP}(\mathrm{SI}=0.31, \mathrm{JI}=0.184)$.

The NMDS identified two major groups (Fig 4). WS, WR, CS and CR constituted one group, while WP and CP formed the other group. They were distantly related with significant difference (ANOSIM R $=1, P=0.04$ ). The root fungal communities from the rosette grass and switchgrass were closely related, and were distinct from those from the pine host. CR and CS from Collier's Mills clustered as a subgroup and separated from another subgroup including WR and WS from Wharton State Forest (Fig 4). However, the ANOSIM test suggested that the difference between these two subgroups is not significant (ANOSIM R $=0.75, P=0.33$ ).

\section{Discussion}

\subsection{Leotiomycetes and edaphic factors}

In the acidic, oligotrophic pine barrens ecosystem, we found that Leotiomycetes fungi 
account for a relatively high proportion of the root endophyte communities. Thirty-two species in eight genera were identified to belong to Leotiomycetes, including Rutstroemia, Lachnum, Meliomyces, Acephala, Phialocephala, Mollisia, Acidomelania, and Barrenia (Fig 1). In other ecosystems, Leotiomycetes usually constitute less than $15 \%$ of the root endophytic fungi according to a number of published papers on poaceous plants, conifers and brassicaceous herbs (Keim et al. 2014; Sánchez Márquez et al. 2007, 2010; Yuan et al. 2010). In our preliminary study (Luo et al. 2014a), the root fungal community in Poaceae grasses in the New Jersey Pine Barrens was compared with that of the Yunnan sub/tropical rain forest. The results showed that $22 \%$ of fungal isolates from the former belonged to Leotiomycetes, while the latter counterpart had only $1.8 \%$ Leotiomycetes. In this study, we focused on three common native plant species in the pine barrens and sampled more extensively. The percentage of Leotiomycetes ranged from 29\% (rosette grass in the Wharton State Forest) to $75 \%$ (switchgrass in the Wharton State Forest) in the six communities analyzed here, which is significantly higher than those reported in other ecosystems.

Leotiomycetes are also frequently found from coniferous and ericaceous roots in the nutrient-limiting boreal and arctic area (Mundra et al. 2015; Sieber and Grünig 2006; Vrålstad et al. 2002). For instance, a total of $6.65 \%$ of the reads (11.54\% OTUs) were represented from Bistorta vivipara root in the Arctic according to a pyrosequencing study (Mundra et al. 2015). The results from a recent global survey using pyrosequencing showed that Leotiomycetes formed $7.1 \%$ of the total soil fungal community, within which the Arctic had the highest (about 25\%) and the tropical savannas and tropical forests had the least Leotiomycetes (1-2\%). Although the soil and root are different habitats, the similar trend also was observed in our grass root fungal survey (Luo et al. 2014a), indicating that edaphic factors play a key role in determining the distribution of soil and root-associated Leotiomycetes.

Geographic locality also was suggested as a factor determining fungal communities (Herrera et al. 2010; Sánchez Márquez et al. 2008). The two sampling locations in this study are only $64 \mathrm{~km}$ apart and have similar soil properties (Table S2). As expected, location did not show significant impact on root fungal endophytes from this study (Fig 4, Table 2). Similar results were also reported from other studies (Loro et al. 2012; Macia-Vicente et al. 2008), in which fungal root endophytic communities were more influenced by the edaphic factors rather than location.

Despite the ubiquity of plant root endophytic fungi, their ecological functions in nature remain elusive. Many researchers in this field speculated that certain endophytes function as mycorrhizae that increase host plant stress tolerance (Mandyam and Jumpponen 2005; Knapp et al. 2012; Sieber and Grünig 2013). However, the specific sources of stress have not been identified and the host-fungus interaction experiments reported to date often produced variable or inconsistent results, ranging from pathogenic to mutually beneficial interactions (Mandyam and Jumpponen 2005). The ecological functions of the root-colonizing Leotiomycetes from the pine barrens also are unclear but some evidence 
indicated that some of them likely play a role in increasing the plant hosts' fitness in the poor nutrient environment, or protection against root pathogenic fungi (Terhonen et al. 2014). Our plant-fungal interaction experiments showed that Acidomelania panicicola and Barrenia panicia, two newly described Leotiomycetes fungi we isolated from the New Jersey Pine Barrens wild switchgrass root promoted switchgrass root hair growth under low nutrient conditions (Walsh et al. 2014, 2015). In addition, the ITS sequence of $A$. panicicola and B. panicia each had over 50 matches in GenBank ( $>97 \%$ identities) from a broad geographic range (Africa, Asia, Europe, Central, North and South America). Despite the wide distribution, the matched samples were all from the roots of plants in acidic and infertile soils, similar to the pine barrens (Walsh et al. 2015). Further studies are needed to better understand the ecological functions of these extensively colonizing Leotiomycetes in the pine barrens.

\subsection{Host specificity of root fungal endophytes}

Another finding from this study is that host plants likely play a role in shaping root endophytic fungal communities. For example, Pseudophialophora, a grass root associated genus we recently described (Luo et al. 2014b, 2015b) was not found from any pine samples in this study. Fungi with host specificity for pine were also revealed in this study, e.g., Phialocephala fortinii and Meliniomyces species. Another example is Barrenia, within which $B$. panicia was only from grass while $B$. taeda was only from pine (Walsh et al. 2015). Pitch pine is a woody gymnosperm plant obligatorily bearing ectomycorrhiza, while the two Poaceae grasses are herbaceous monocots generally forming arbuscular mycorrhiza (Smith and Read 2008). The genus Meliniomyces was reported to include ectomycorrhizal species (Hambleton and Sigler 2005). In this study, we identified four Meliniomyces species from the pine roots and whether they also are ectomycorrhizal symbionts needs further studies to verify.

There were 42 fungal species found exclusively from pitch pine root, 21 from rosette grass and 14 from switchgrass (Fig 5). However, only four fungal species were found from all the three hosts, i.e., Chaetomium aureum, Mollisia sp., Acephala sp4., and Phoma herbarum (Figs 1 and 5). More species (12 species) were shared by the two grasses than those between pine and switchgrass grass ( 6 species), or rosette grass ( 5 species). In addition to the four common fungal species listed above, Codinaeopsis sp., Pseudophialophora sp4, Pseudophialophora panicorum, Lachlum virgineum, Lachnum sp., Acephala sp3, Leotiomycetes sp., and Phoma sp. were found from both of the grasses; Fusarium verticillioides and Umbelopsis dimorpha were from the pitch pine and switchgrass; Umbelopsis isabellina was shared by the pine and rosette grass (Figs 1 and 5). These results suggested host specificity of certain fungal species.

The difference between the grass and pine fungal communities was significant with only $8 \%$ shared fungal species, while the host specificity was not well supported between the two grasses based on the ANOSIM test. Similar results were reported in a number of published papers (Hoff et al. 2004; Kernaghan and Patriquin 2011; Khidir et al. 2010; 
Macia-Vicente et al. 2008). Khidir et al. (2010) reported a general suite of root fungal endophytes from two Poaceae species, which was different from the Agavaceae weed. Hoff et al. (2004) and Kernaghan and Patriquin (2011) found that the root endophytes showed little host specificity within the Pinaceae family. No host specificity was observed when Helotiales fungi were investigated from Ericaceae species (Walker et al. 2011). Our data corroborate other published results that host specificity of root endophytes is evident at the family level of the plants (Hoff et al. 2004; Kernaghan and Patriquin 2011; Walker et al. 2011).

\subsection{Pine barrens plant roots-a rich reservoir of undescribed fungi}

Our previous survey on grass root associated fungi from the pine barrens and Yunnan sub/tropical rain forest showed that pine barrens plant roots were a rich reservoir of novel fungi with about $47 \%$ being undescribed species (Luo et al. 2014a). This study added more data and corroborated this finding. To date, a total of 136 fungal species have been identified from 1,011 cultures isolated from pine barrens plant roots, of which 62 species $(46 \%)$ are likely undescribed (Luo et al. 2014a, 2014b, 2015b; Walsh et al. 2014, 2015, unpublished data). It is possible that some species may be described but have not been sequenced. However, it was estimated that over $90 \%$ of fungal species have not been discovered and the unmatched sequences more likely are new taxa (Hibbett and Taylor 2013). Furthermore, we also check morphology to confirm their novelty. We are aware that ITS sequences are highly variable at family or higher levels and therefore are not appropriate to infer phylogenetic relations for all fungal taxa collected in this study. Fig 1 is shown only to demonstrate overall fungal diversity. Our species identification was based on a number of separate phylogenetic analyses for each individual OTU (not shown due to limited space), rather than only based on BLAST or the ITS tree. Six-locus (SSU, LSU, ITS, EF-1alpha, MCM7 and RPB1) phylogenetic analysis was done with the new Pseudophialophora and Magnaporthiopsis species (Luo et al. 2014b, 2015b), and three-locus phylogeny was generated when proposed the new Acidomelania and Barrenia species (Walsh et al. 2014, 2015). In addition, our phylogenomic analysis based on over 200 genes further supported recognition of the new Pseudophialophora Magnaporthiopsis species (Luo et al. 2015a).

The New Jersey Pine Barrens has about 850 plant species (State of New Jersey Pinelands Commission, 2012) but only a handful of them have been studied for their root endophytes (Luo et al. 2014a, 2014b, 2015b; Walsh et al. 2014, 2015). Based on the host association data (Fig 5) and our species accumulation curves (Fig 2), further sampling in the pine barrens will likely result in uncovering more novel fungal species. These discoveries will fill in the missing lineages of the fungal tree of life, shed light on their functions in the ecosystems, and contribute to finding the principles of fungal distribution and community assemblage.

\section{Acknowledgements}


This work was supported by the National Science Foundation (grant numbers DEB 1145174 and DEB 1452971 to Zhang) and the Rutgers Center for Turfgrass Science. 
Table and Figure legends:

Table 1 - Comparison of fungal communities associated with plant roots from different locations and hosts.

Table 2 - Similarity of fungal communities from grass roots between different locations and hosts. Sørenson's index is showed above the diagonal, while Jaccard's index is below the diagonal.

Fig 1 - Maximum likelihood tree inferred from ITS sequences of 92 OTUs obtained in this study. Branch values $(\geq 50 \%)$ of ML bootstrap proportions are noted above internodes. Bars show the number of isolates from corresponding plant hosts.

Fig 2 - Species accumulation curves of root associated fungi from rosette grass $(R)$, switchgrass (S) and pitch pine (P) from Collier's Mills (C) and Wharton State Forest $(\mathrm{W})$ in New Jersey Pine Barrens.

Fig 3 - Relative abundance and composition of root associated fungal classes found in rosette grass (R), switchgrass (S) and pitch pine (P) from Collier's Mills (C) and Wharton State Forest (W) in New Jersey Pine Barrens.

Fig 4 - Non-metric multidimensianal scaling (NMDS) of root associated fungi from rosette grass (R), switchgrass (S) and pitch pine (P) from Collier's Mills (C) and Wharton State Forest (W) in the New Jersey Pine Barrens.

Fig 5 - Venn diagram of shared root fungal species across the three host plants. 


\section{REFERENCES}

Bills GF, Foster MS, 2004. II - FORMULAE FOR SELECTED MATERIALS USED TO ISOLATE AND STUDY FUNGI AND FUNGAL ALLIES, Biodiversity of Fungi. Academic Press, Burlington, pp. 595-618.

Butin H, 1986. Endophytic fungi in green needles of norway spruce picea abies karst. Zeitschrift fuer Mykologie 52: 335-345.

Colwell RK, Chao A, Gotelli NJ, Lin S-Y, Mao CX, Chazdon RL, Longino JT, 2012. Models and estimators linking individual-based and sample-based rarefaction, extrapolation and comparison of assemblages. Journal of Plant Ecology 5: 3-21.

Davison J, Moora M, Öpik M, Adholeya A, Ainsaar L, Bâ A, Burla S, Diedhiou AG, Hiiesalu I, Jairus T, Johnson NC, Kane A, Koorem K, Kochar M, Ndiaye C, Pärtel M, Reier Ü, Saks Ü, Singh R, Vasar M, Zobel M, 2015. Global assessment of arbuscular mycorrhizal fungus diversity reveals very low endemism. Science 349: 970-973.

Edgar RC, 2010. Search and clustering orders of magnitude faster than BLAST. Bioinformatics 26: 2460-2461.

Fisher PJ, Petrini LE, Sutton BC, Petrini O, 1995. A study of fungal endophytes in leaves, stems and roots of Gynoxis oleifolia Muchler (Compositae) from Ecuador. Nova Hedwigia 60: 589-594.

Forman RTT, 1998. Pine Barrens: Ecosystem and Landscape. Academic Press, New York.

Gazis R, Rehner S, Chaverri P, 2011. Species delimitation in fungal endophyte diversity studies and its implications in ecological and biogeographic inferences. Molecular Ecology 20: 3001-3013.

Grünig CR, Duò A, Sieber TN, Holdenrieder O, 2008a. Assignment of species rank to six reproductively isolated cryptic species of the Phialocephala fortinii s.l.-Acephala applanata species complex. Mycologia 100: 47-67.

Grünig CR, McDonald BA, Sieber TN, Rogers SO, Holdenrieder O, 2004. Evidence for subdivision of the root-endophyte Phialocephala fortinii into cryptic species and recombination within species. Fungal Genetics and Biology 41: 676-687.

Grünig CR, Queloz V, Sieber TN, Holdenrieder O, 2008b. Dark septate endophytes (DSE) of the Phialocephala fortiniis.1. -Acephala applanataspecies complex in tree roots: classification, population biology, and ecology. Botany 86: 1355-1369.

Guindon S, Dufayard JF, Lefort V, Anisimova M, Hordijk W, Gascuel O, 2010. New algorithms and methods to estimate maximum-likelihood phylogenies: assessing the performance of PhyML 3.0. Systematic Biology 59: 307-321.

Hall TA, 1999. BioEdit: a user-friendly biological sequence alignment editor and analysis program for Windows 95/98/NT. Nucleic Acids Symposium Series 41: 95-98.

Hambleton S, Sigler L, 2005. Meliniomyces, a new anamorph genus for root-associated fungi with phylogenetic affinities to Rhizoscyphus ericae (三 Hymenoscyphus ericae), Leotiomycetes. Studies in Mycology 53: 1-27.

Herrera J, Khidir HH, Eudy DM, Porras-Alfaro A, Natvig DO, Sinsabaugh RL, 2010. 
Shifting fungal endophyte communities colonize Bouteloua gracilis: effect of host tissue and geographical distribution. Mycologia 102: 1012-1026.

Hibbett DS, Taylor JW, 2013. Fungal systematics: is a new age of enlightenment at hand? Nature Reviews Microbiology 11: 129-133.

Hirsch G, Braun U, 1992. Communities of parasitic microfungi, in: Winterhoff W (ed), Fungi in vegetation science. Springer Netherlands, Dordrecht, pp. 225-250.

Hoff JA, Klopfenstein NB, McDonald GI, Tonn JR, Kim MS, Zambino PJ, Hessburg PF, Rogers JD, Peever TL, Carris LM, 2004. Fungal endophytes in woody roots of Douglas-fir (Pseudotsuga menziesii) and ponderosa pine (Pinus ponderosa). Forest Pathology 34: 255-271.

Joffe JS, Watson CW, 1933. Soil Profile Studies: V. Mature podzols. Soil Science 35: 313-332.

Jumpponen A, Trappe JM, 1998. Dark septate endophytes: a review of facultative biotrophic root-colonizing fungi. New Phytologist 140: 295-310.

Keim J, Mishra B, Sharma R, Ploch S, Thines M, 2014. Root-associated fungi of Arabidopsis thaliana and Microthlaspi perfoliatum. Fungal Diversity 66: 99-111.

Kernaghan G, Patriquin G, 2011. Host associations between fungal root endophytes and boreal trees. Microbial Ecology 62: 460-473.

Khidir HH, Eudy DM, Porras-Alfaro A, Herrera J, Natvig DO, Sinsabaugh RL, 2010. A general suite of fungal endophytes dominate the roots of two dominant grasses in a semiarid grassland. Journal of Arid Environments 74: 35-42.

Kleczewski NM, Bauer JT, Bever JD, Clay K, Reynolds HL, 2012. A survey of endophytic fungi of switchgrass (Panicum virgatum) in the Midwest, and their putative roles in plant growth. Fungal Ecology 5: 521-529.

Knapp DG, Pintye A, Kovacs GM, 2012. The dark side is not fastidious--dark septate endophytic fungi of native and invasive plants of semiarid sandy areas. PloS One 7: e32570.

Loro M, Valero-Jiménez CA, Nozawa S, Márquez LM, 2012. Diversity and composition of fungal endophytes in semiarid Northwest Venezuela. Journal of Arid Environments 85: 46-55.

Luo J, Qiu H, Cai G, Wagner NE, Bhattacharya D, Zhang N, 2015a. Phylogenomic analysis uncovers the evolutionary history of nutrition and infection mode in rice blast fungus and other Magnaporthales. Scientific Reports 5: 9448.

Luo J, Walsh E, Blystone D, Zhang N, 2015b. Five new Pseudophialophora species from grass roots in the oligotrophic pine barrens ecosystem. Fungal Biology 119: $1205-1215$.

Luo J, Walsh E, Naik A, Zhuang W, Zhang K, Cai L, Zhang N, 2014a. Temperate pine barrens and tropical rain forests are both rich in undescribed fungi. PloS One 9: e103753.

Luo J, Walsh E, Zhang N, 2014b. Four new species in Magnaporthaceae from grass roots in New Jersey Pine Barrens. Mycologia 106: 580-588. 
Luo J, Zhang N, 2013. Magnaporthiopsis, a new genus in Magnaporthaceae (Ascomycota). Mycologia 105: 1019-1029.

Macia-Vicente JG, Jansson HB, Abdullah SK, Descals E, Salinas J, Lopez-Llorca LV, 2008. Fungal root endophytes from natural vegetation in Mediterranean environments with special reference to Fusarium spp. FEMS Microbiology Ecology 64: 90-105.

Mandyam K, Jumpponen A, 2005. Seeking the elusive function of the root-colonising dark septate endophytic fungi. Studies in Mycology 53: 173-189.

Mundra S, Halvorsen R, Kauserud H, Muller E, Vik U, Eidesen PB, 2015. Arctic fungal communities associated with roots of Bistorta vivipara do not respond to the same fine-scale edaphic gradients as the aboveground vegetation. New Phytologist 205: $1587-1597$.

Newton AC, Haigh JM, 1998. Diversity of ectomycorrhizal fungi in Britain: a test of the species-area relationship, and the role of host specificity. New Phytologist 138: 619-627.

Nilsson RH, Kristiansson E, Ryberg M, Hallenberg N, Larsson KH, 2008. Intraspecific ITS variability in the kingdom fungi as expressed in the international sequence databases and its implications for molecular species identification. Evolutionary Bioinformatics Online 4: 193-201.

Nylander JAA, 2004. MrModeltest v2. Program distributed by the author. Evolutionary Biology Centre, Uppsala University.

O'Brien HE, Parrent JL, Jackson JA, Moncalvo JM, Vilgalys R, 2005. Fungal community analysis by large-scale sequencing of environmental samples. Applied and Environmental Microbiology 71: 5544-5550.

Oksanen J, 2015. Multivariate analysis of ecological communities in R: vegan tutorial.

Rodriguez RJ, White JF, Jr., Arnold AE, Redman RS, 2009. Fungal endophytes: diversity and functional roles. New Phytologist 182: 314-330.

Sánchez Márquez S, Bills GF, Domínguez Acuña L, Zabalgogeazcoa I, 2010. Endophytic mycobiota of leaves and roots of the grass Holcus lanatus. Fungal Diversity 41: $115-123$.

Sánchez Márquez S, Bills GF, Zabalgogeazcoa I, 2007. The endophytic mycobiota of the grass Dactylis glomerata. Fungal Diversity 27: 171-195.

Sánchez Márquez S, Bills GF, Zabalgogeazcoa I, 2008. Diversity and structure of the fungal endophytic assemblages from two sympatric coastal grasses. Fungal Diversity 33: $87-100$.

Sieber TN, 2002. Fungal Root Endophytes, in: Waisel Y, Eshel A, Kafkafi U (eds), Plant roots : The Hidden Half. Marcel Dekker, New York, pp. 887-917.

Sieber TN, Grünig CR, 2006. Biodiversity of Fungal Root-Endophyte Communities and Populations, in Particular of the Dark Septate Endophyte Phialocephala fortinii s. 1, in: Schulz BJE, Boyle CJC, Sieber TN (eds), Microbial Root Endophytes. Springer Berlin Heidelberg, Berlin, Heidelberg, pp. 107-132.

Sieber TN, Grünig CR, 2013. Fungal root endophytes., in: Eshel A, Beeckman T (eds), 
Plant Roots - The Hidden Half, 4th ed. CRC Press, Taylor \& Francis Group., Boca Raton, FL, USA, pp. 38-31-38-49.

Smith SE, Read DJ, 2008. Mycorrhizal Symbiosis, 3th ed. Academic Press, London. Tedersoo L, Bahram M, Põlme S, Kõljalg U, Yorou NS, Wijesundera R, Ruiz LV, Vasco-Palacios AM, Thu PQ, Suija A, Smith ME, Sharp C, Saluveer E, Saitta A, Rosas M, Riit T, Ratkowsky D, Pritsch K, Põldmaa K, Piepenbring M, Phosri C, Peterson M, Parts K, Pärtel K, Otsing E, Nouhra E, Njouonkou AL, Nilsson RH, Morgado LN, Mayor J, May TW, Majuakim L, Lodge DJ, Lee SS, Larsson K-H, Kohout P, Hosaka K, Hiiesalu I, Henkel TW, Harend H, Guo L-D, Greslebin A, Grelet G, Geml J, Gates G, Dunstan W, Dunk C, Drenkhan R, Dearnaley J, De Kesel A, Dang T, Chen X, Buegger F, Brearley FQ, Bonito G, Anslan S, Abell S, Abarenkov K, 2014. Global diversity and geography of soil fungi. Science 346.

Tedrow JCF, 1952. Soil Conditions in the Pine Barrens of New Jersey. Bartonia 26: 28-35.

Terhonen E, Keriö S, Sun H, Asiegbu FO, 2014. Endophytic fungi of Norway spruce roots in boreal pristine mire, drained peatland and mineral soil and their inhibitory effect on Heterobasidion parviporum in vitro. Fungal Ecology 9:17-26.

Thompson JD, Gibson TJ, Plewniak F, Jeanmougin F, Higgins DG, 1997. The CLUSTAL_X windows interface: flexible strategies for multiple sequence alignment aided by quality analysis tools. Nucleic Acids Research 25: 4876-4882.

Tuininga AR, Dighton J, 2004. Changes in ectomycorrhizal communities and nutrient availability following prescribed burns in two upland pine oak forests in the New Jersey pine barrens. Canadian Journal of Forest Research 34: 1755-1765.

Turner RS, Johnson AH, Wang D, 1985. Biogeochemistry of Aluminum in McDonalds Branch Watershed, New Jersey Pine Barrens. Journal of Environmental Quality 14: 314-323.

Vrålstad T, Myhre E, Schumacher T, 2002. Molecular diversity and phylogenetic affinities of symbiotic root-associated ascomycetes of the Helotiales in burnt and metal polluted habitats. New Phytologist 155: 131-148.

Walker JF, Aldrich-Wolfe L, Riffel A, Barbare H, Simpson NB, Trowbridge J, Jumpponen A, 2011. Diverse Helotiales associated with the roots of three species of Arctic Ericaceae provide no evidence for host specificity. New Phytologist 191: 515-527.

Walsh E, Luo J, Naik A, Preteroti T, Zhang N, 2015. Barrenia, a new genus associated with roots of switchgrass and pine in the oligotrophic pine barrens. Fungal Biology 119: 1216-1225.

Walsh E, Luo J, Zhang N, 2014. Acidomelania panicicola gen. et sp. nov. from switchgrass roots in acidic New Jersey pine barrens. Mycologia 106: 856-864.

White T, Bruns T, Lee S, Taylor J, 1990. Amplification and direct sequencing of fungal ribosomal RNA genes for phylogenetics, in: Innis M, Gelfand D, Shinsky J, White T (eds), PCR Protocols: A Guide to Methods and Applications. Academic Press, pp. 315-322.

Wood RKS, Graniti A, 1976. Specificity in Plant Diseases. Plenum Press. 
Yuan ZL, Zhang CL, Lin FC, Kubicek CP, 2010. Identity, diversity, and molecular phylogeny of the endophytic mycobiota in the roots of rare wild rice (Oryza granulate) from a nature reserve in Yunnan, China. Applied and Environmental Microbiology 76: $1642-1652$.

Zhou D, Hyde KD, 2001. Host-specificity, host-exclusivity, and host-recurrence in saprobic fungi. Mycological Research 105: 1449-1457.

Zubek S, Piątek K, Naks P, Heise W, Wayda M, Mleczko P, 2010. Fungal Root Endophyte Colonization of Fern and Lycophyte Species from the Celaque National Park in Honduras. American Fern Journal 100: 126-136. 


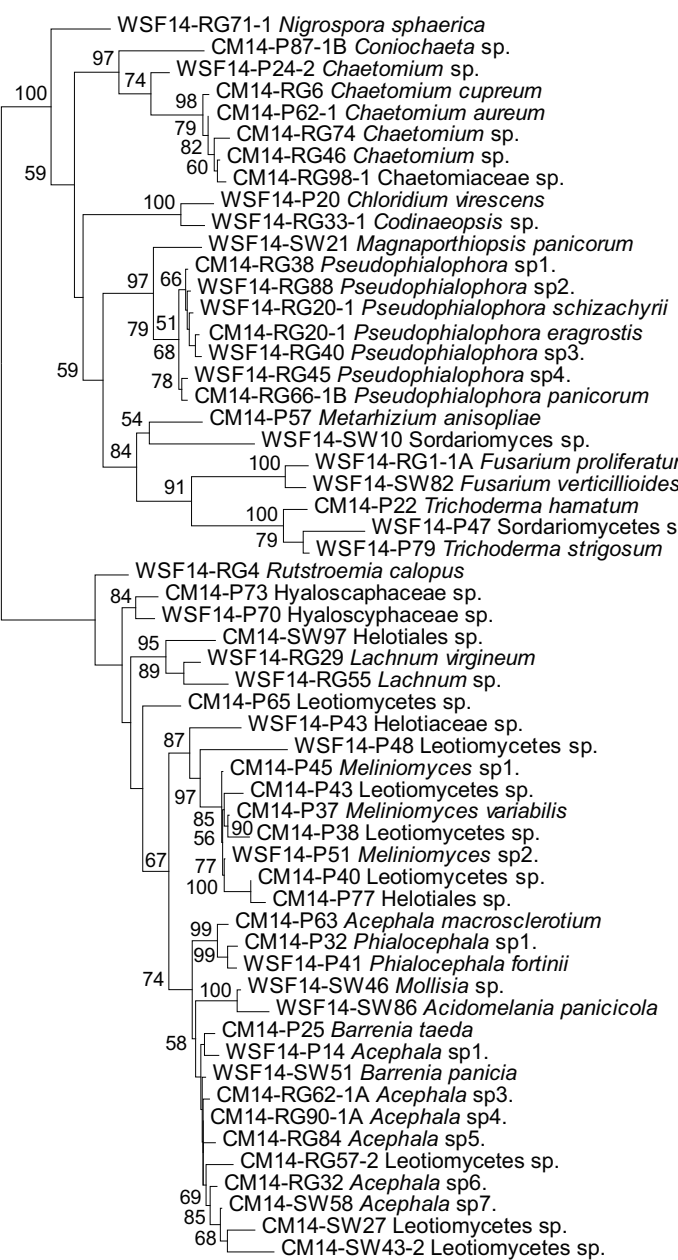

88 CM14-P21 Talaromyces verruculosus

WSF14-P81 Aspergillus cerrinus

CM14-RG52 Penicillium chrysogenum

WSF14-SW81 Penicillium griseolum

68 CM14-P53 Penicillium daleae

CM14-RG30-1A Penicillium janthinellum

CM14-P12 Penicillium citreonigrum

64 CM14-P15 Penicillium sp.

99 WSF14-P86 Cladosporium cladosporioides

99 W WSF14-RG42 Teratosphaeriaceae sp. WSF14-P95 Cenococcum sp.

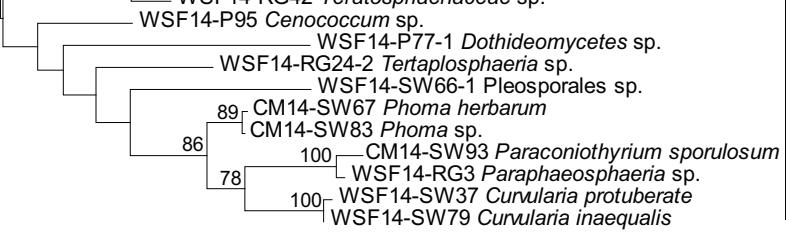

0.2

100 - WSF14-RG57 Mycoacia fuscoatra

WSF14-RG38 Phlebia tremellosa

WSF14-P34 Ceratobasidium sp.

66 CM14-RG2 Mycena alnetorum WS14-SW74 Mititi scytinostroma sp. 4-SW74 Mortierella parvispora CM14-P16 Mortierellales sp.

100 CM14-P83 Mucoromycotina sp.

${ }_{100}$ CM14-P52-2 Umbelopsis dimorpha

1 CM14-RG68 Umbelopsis

WSF14-P89 Mucoromycotina sp.

Number of isolates
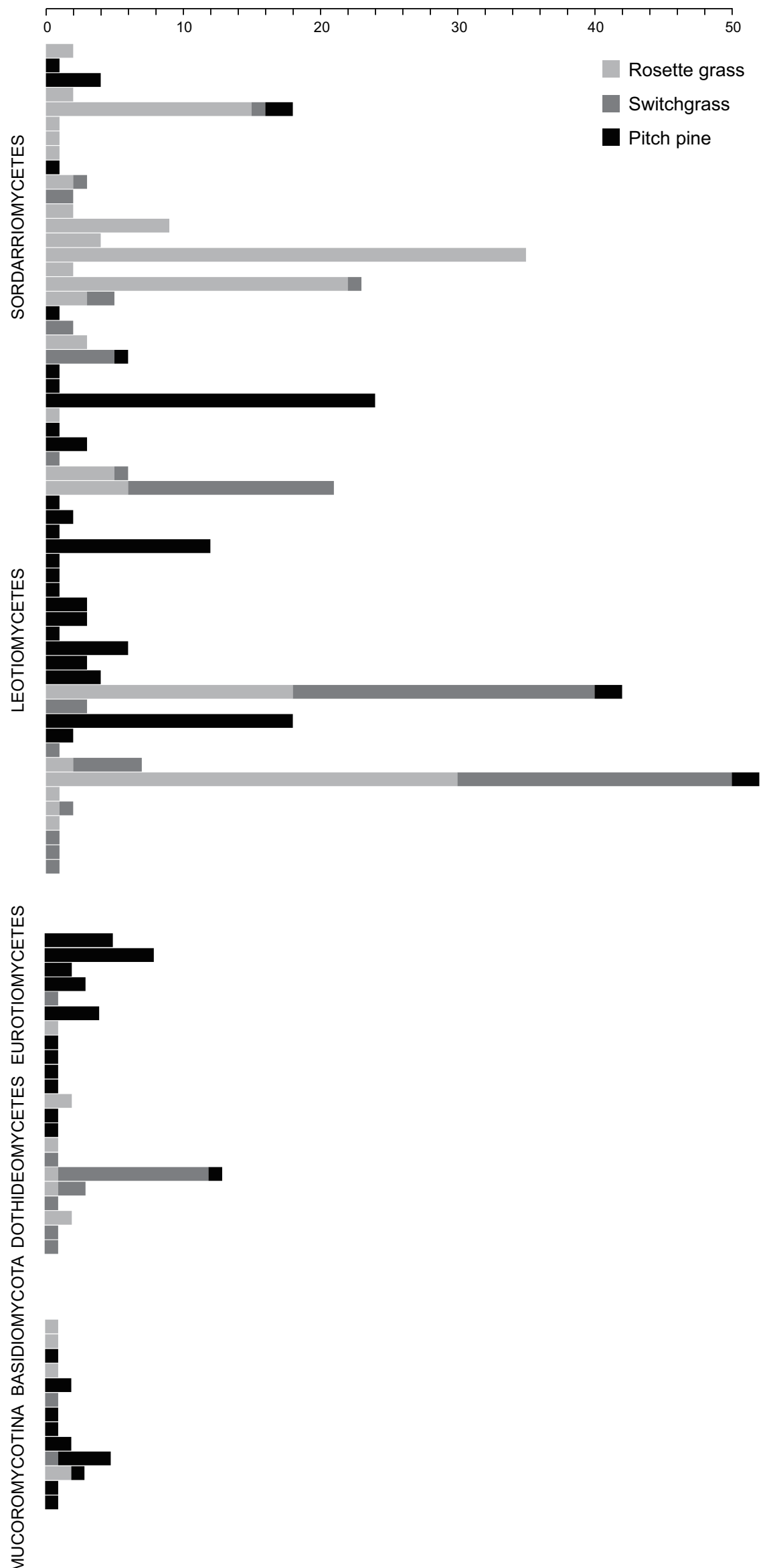


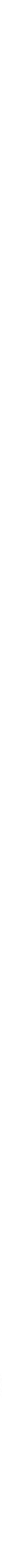

Figure2

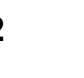
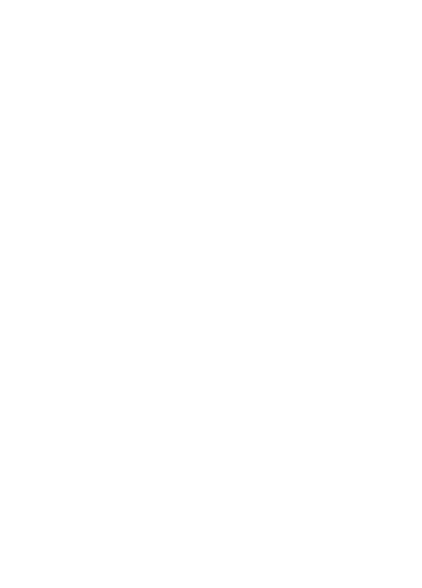

$$
\text { . }
$$

Figure
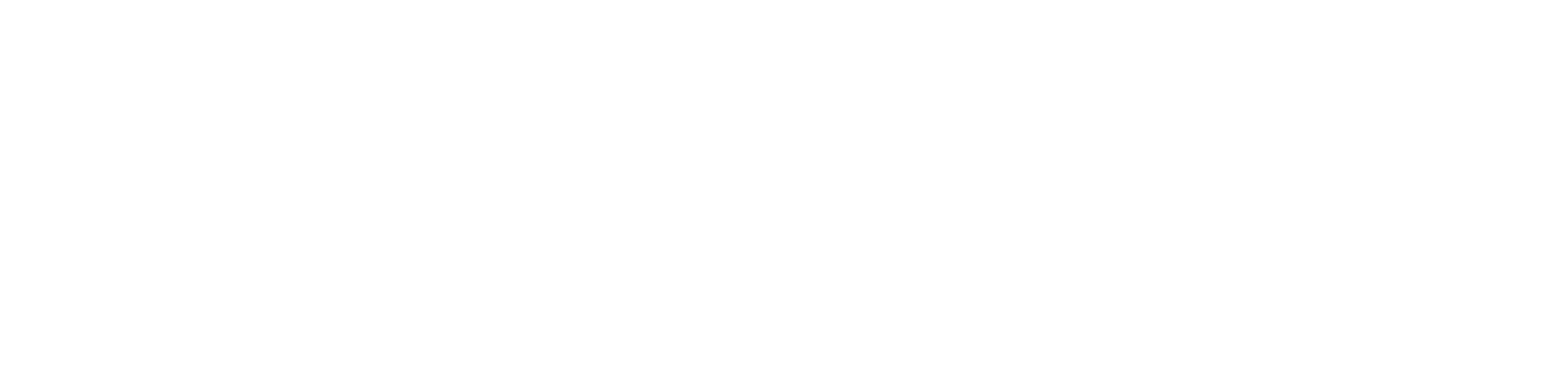

(1)

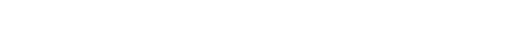


- Leotiomycetes $\square$ Sordariomycetes $\square$ Dothideomycetes $\square$ Others

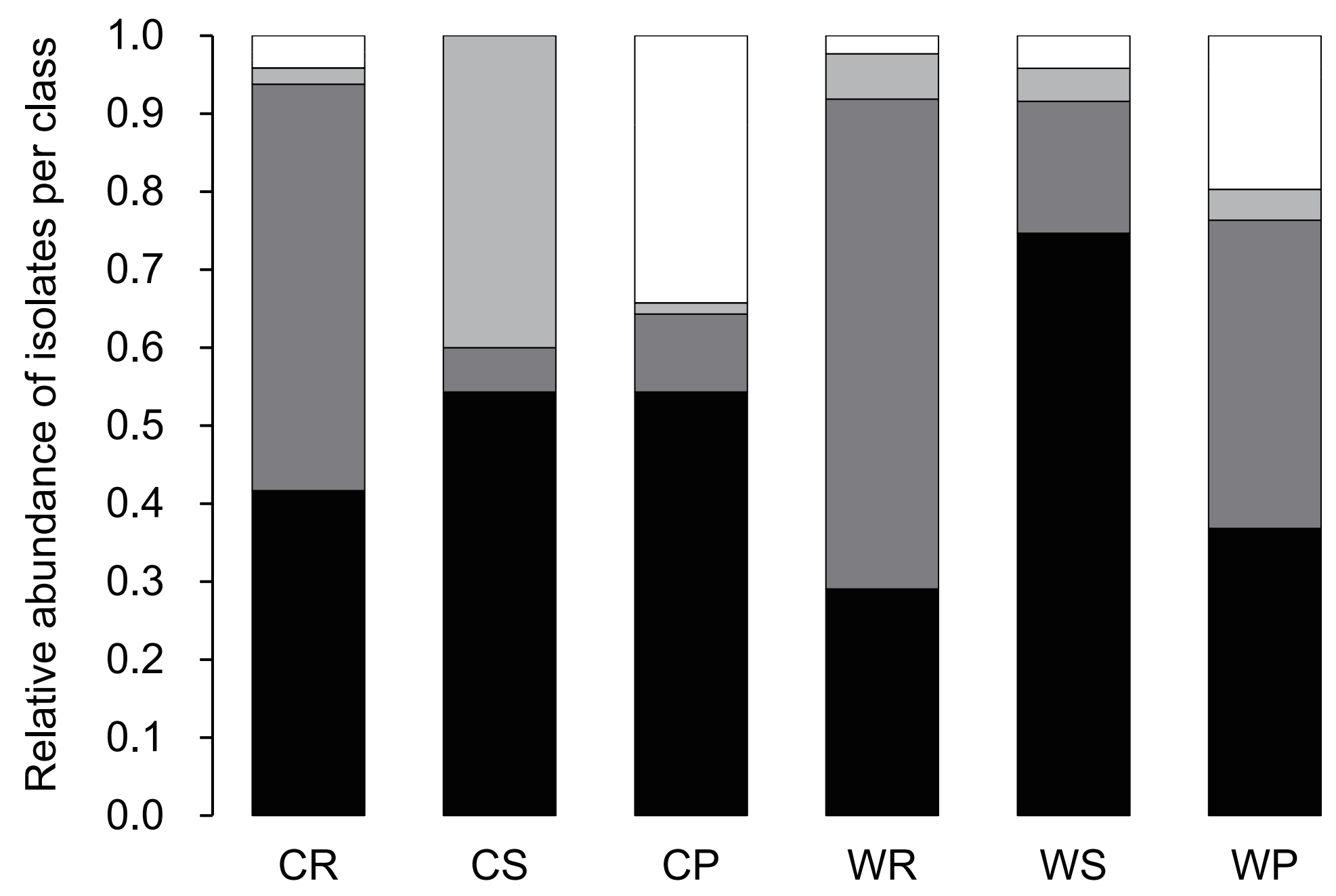




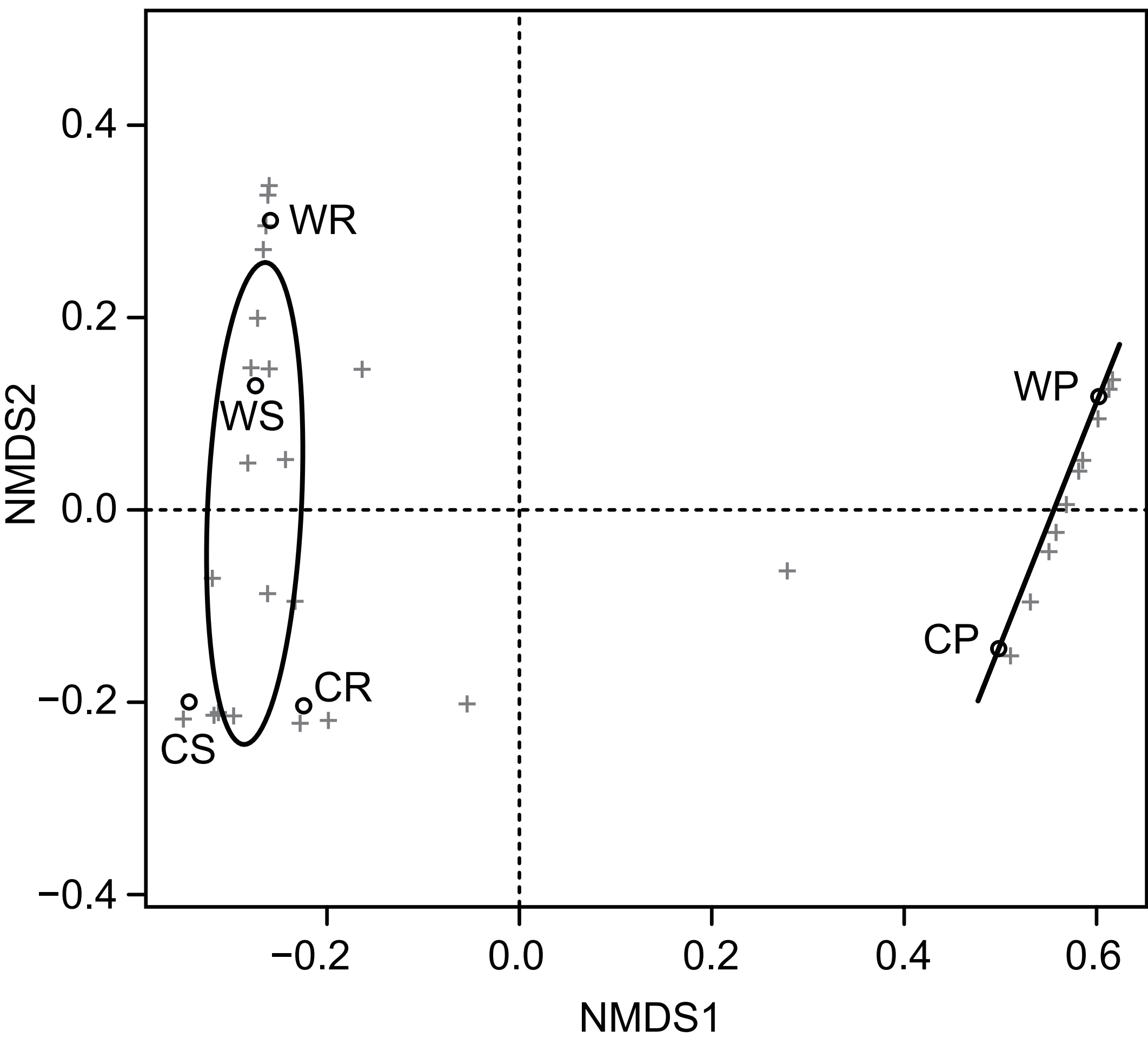




\section{Rosette grass}

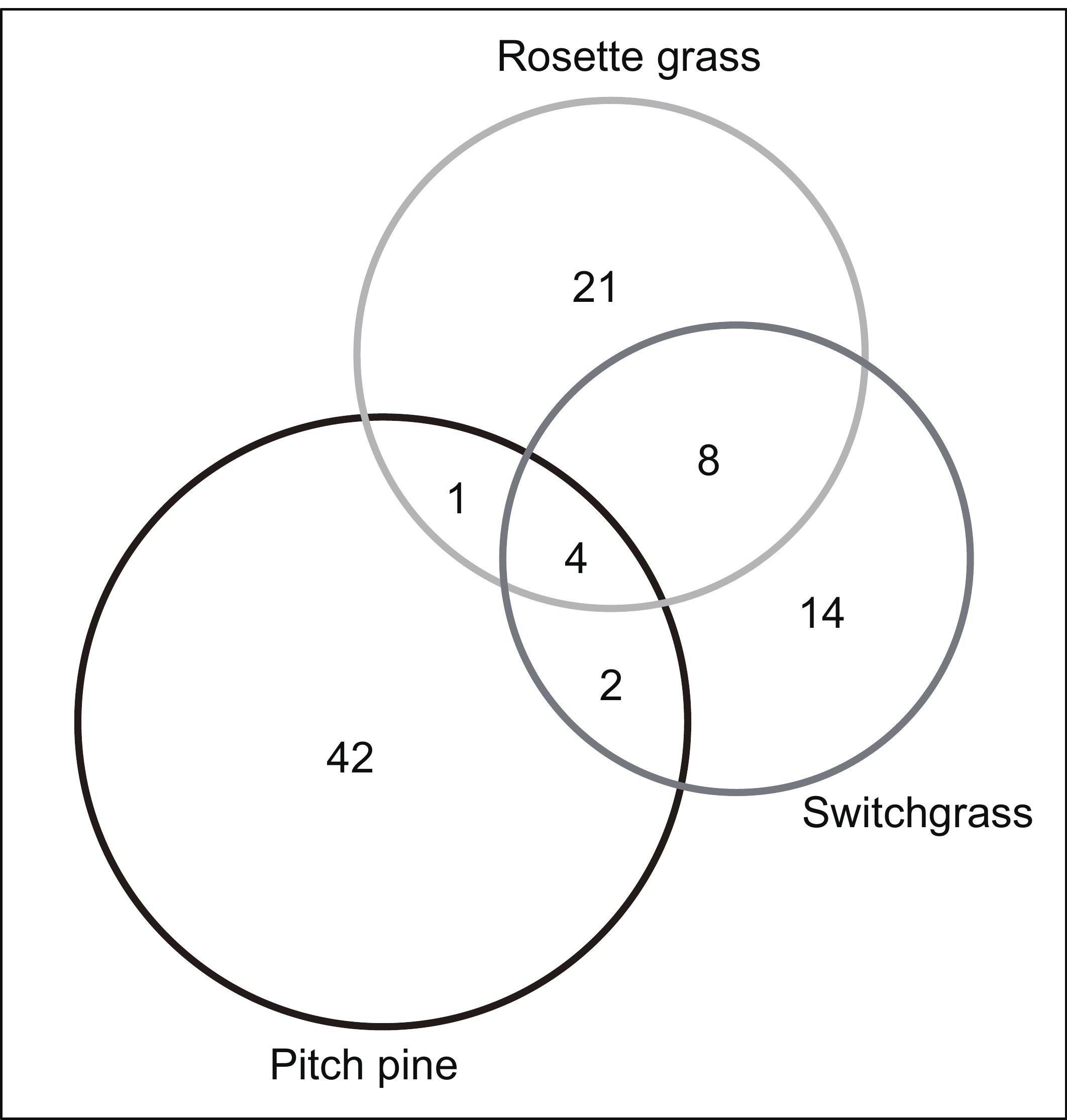

Figure5 
Table 1 - Comparison of fungal communities associated with plant roots from different locations and hosts.

\begin{tabular}{|c|c|c|c|c|c|c|c|}
\hline & $\begin{array}{l}\text { Number } \\
\text { of root } \\
\text { samples }\end{array}$ & $\begin{array}{l}\text { Number } \\
\text { of fungal } \\
\text { isolates }\end{array}$ & $\begin{array}{l}\text { Number } \\
\text { of fungal } \\
\text { species }\end{array}$ & Chao1 & $\begin{array}{l}\text { Fisher's } \\
\text { alpha }\end{array}$ & $\begin{array}{l}\text { Shannon's } \\
\text { index }\end{array}$ & Most frequently isolated fungal species \\
\hline $\begin{array}{l}\text { Colliers Mills } \\
\text { _Rosette grass } \\
\text { (CR) }\end{array}$ & 10 & 96 & 19 & 35 & 7.1 & 2.05 & $\begin{array}{l}\text { Pseudophialophora eragrostis }(28.1 \%) \text {, } \\
\text { Acephala sp4. (27.1\%), Chaetomium aureum } \\
(15.6 \%)\end{array}$ \\
\hline $\begin{array}{l}\text { Colliers Mills } \\
\text { _Switchgrass } \\
\text { (CS) }\end{array}$ & 10 & 35 & 13 & 30 & 7.49 & 2.01 & $\begin{array}{l}\text { Phoma herbarum }(31.4 \%) \text {, Acephala } \mathrm{sp} 4 . \\
(28.6 \%), \text { Mollisia } \mathrm{sp} .\end{array}$ \\
\hline $\begin{array}{l}\text { Colliers Mills } \\
\text { _Pitch pine }(\mathrm{CP})\end{array}$ & 10 & 70 & 33 & 54 & 24.38 & 3.11 & $\begin{array}{l}\text { Phialocephala sp2. (21.4\%), Acephala } \\
\text { macrosclerotium (8.6\%), Umbelopsis } \\
\text { dimorpha }(5.7 \%)\end{array}$ \\
\hline $\begin{array}{l}\text { Wharton State } \\
\text { Forest } \\
\text { _Rosette grass } \\
\text { (WR) }\end{array}$ & 10 & 86 & 20 & 21 & 8.19 & 2.56 & $\begin{array}{l}\text { Pseudophialophora sp4. (25.6\%), } \\
\text { Pseudophialophora sp2. (10.5\%), Mollisia } \\
\text { sp. }(9.3 \%), \text { Pseudophialophora eragrostis } \\
(9.3 \%)\end{array}$ \\
\hline
\end{tabular}




\begin{tabular}{|c|c|c|c|c|c|c|c|}
\hline $\begin{array}{l}\text { Wharton State } \\
\text { Forest } \\
\text { _Switchgrass } \\
\text { (WS) }\end{array}$ & 10 & 71 & 19 & 37 & 8.5 & 2.3 & $\begin{array}{l}\text { Mollisia sp. }(26.8 \%), \text { Lachnum sp. }(21.1 \%) \\
\text { Acephala sp4. }(14.1 \%)\end{array}$ \\
\hline $\begin{array}{l}\text { Wharton State } \\
\text { Forest } \\
\text { _Pitch pine (WP) }\end{array}$ & 10 & 76 & 25 & 34 & 12.99 & 2.63 & $\begin{array}{l}\text { Trichoderma strigosum }(30.3 \%) \text {, } \\
\text { Meliniomyces sp1. (13.2\%), Aspergillus } \\
\text { cerrinus }(6.6 \%)\end{array}$ \\
\hline
\end{tabular}


Table 2 - Similarity of fungal communities from grass roots between different locations and hosts. Sørenson's index is showed above the diagonal, while Jaccard's index is below the diagonal.

\begin{tabular}{|c|c|c|c|c|c|c|}
\hline & $\begin{array}{l}\text { Colliers Mills } \\
\text { _Rosette grass } \\
\text { (CR) }\end{array}$ & $\begin{array}{l}\text { Colliers Mills } \\
\text { _Switchgrass } \\
\text { (CS) }\end{array}$ & $\begin{array}{l}\text { Colliers Mills } \\
\text { _Pitch pine }(\mathrm{CP})\end{array}$ & $\begin{array}{l}\text { Wharton State } \\
\text { Forest_Rosette } \\
\text { grass (WR) }\end{array}$ & $\begin{array}{l}\text { Wharton State } \\
\text { Forest_Switchgra } \\
\text { ss (WS) }\end{array}$ & $\begin{array}{l}\text { Wharton State } \\
\text { Forest_Pitch pine } \\
\text { (WP) }\end{array}$ \\
\hline $\begin{array}{l}\text { Colliers Mills } \\
\text { _Rosette grass (CR) }\end{array}$ & & 0.44 & 0.19 & 0.26 & 0.21 & 0.05 \\
\hline $\begin{array}{l}\text { Colliers Mills } \\
\text { _Switchgrass (CS) }\end{array}$ & 0.28 & & 0.17 & 0.18 & 0.25 & 0.05 \\
\hline $\begin{array}{l}\text { Colliers Mills } \\
\text { _Pitch pine (CP) }\end{array}$ & 0.11 & 0.10 & & 0.08 & 0.12 & 0.31 \\
\hline $\begin{array}{l}\text { Wharton State } \\
\text { Forest_Rosette } \\
\text { grass (WR) }\end{array}$ & 0.15 & 0.10 & 0.04 & & 0.41 & 0.04 \\
\hline $\begin{array}{l}\text { Wharton State } \\
\text { Forest_Switchgrass } \\
\text { (WS) }\end{array}$ & 0.12 & 0.14 & 0.06 & 0.26 & & 0.09 \\
\hline
\end{tabular}




\begin{tabular}{|l|l|l|l|l|l|l|}
\hline Wharton State & 0.02 & 0.03 & 0.18 & 0.02 & 0.05 \\
Forest_Pitch pine & & & & & & \\
(WP) & & & & & \\
\hline
\end{tabular}

